\title{
Preferential Attraction of Oviposition-Ready Oriental Fruit Flies to Host Fruit Odor over Protein Food Odor
}

\author{
Gwang-Hyun Roh ${ }^{1,2}$, Paul E. Kendra ${ }^{3}$ and Dong H. Cha ${ }^{1, *}$ \\ 1 USDA-ARS, US Pacific Basin Agricultural Research Center, Hilo, HI 96720, USA; \\ roh.gwanghyun82@gmail.com \\ 2 Oak Ridge Institute for Science and Education, Oak Ridge, TN 37830, USA \\ 3 USDA-ARS, Subtropical Horticulture Research Station, Miami, FL 33158, USA; paul.kendra@usda.gov \\ * Correspondence: dong.cha@usda.gov
}

check for updates

Citation: Roh, G.-H.; Kendra, P.E.; Cha, D.H. Preferential Attraction of Oviposition-Ready Oriental Fruit Flies to Host Fruit Odor over Protein Food Odor. Insects 2021, 12, 909. https: / / doi.org/10.3390/ insects12100909

Academic Editor: Sylvia Anton

Received: 13 September 2021 Accepted: 29 September 2021 Published: 6 October 2021

Publisher's Note: MDPI stays neutral with regard to jurisdictional claims in published maps and institutional affiliations.

Copyright: (c) 2021 by the authors. Licensee MDPI, Basel, Switzerland. This article is an open access article distributed under the terms and conditions of the Creative Commons Attribution (CC BY) license (https:// creativecommons.org/licenses/by/ $4.0 /)$.
Simple Summary: Oriental fruit fly, Bactrocera dorsalis, is one of the most destructive invasive pests of tropical fruit and vegetable crops worldwide. Current oriental fruit fly quarantine programs focus heavily on the control and surveillance of male flies, which is less effective for mitigating the impact caused by female populations. We investigated the relationship between olfactory preference and oviposition outcome of oriental fruit flies. In laboratory bioassays using similarly aged (14-16 day old) cohorts of mated females, some females preferred host fruit odors over protein food odor (torula yeast), while some preferred protein odor. The females that preferred host fruit odor had 2.1 times greater egg load and laid 2.4 times more eggs than females that preferred protein odor. Our results suggest that mated female oriental fruit flies with a preference for host fruit odor are likely to be in an imminent oviposition-ready physiological status, while mated females that prefer torula yeast odor are likely more protein-hungry and need more protein to produce the critical egg load necessary for oviposition.

Abstract: Olfaction plays a key role in the location of food and oviposition resources by tephritid fruit flies. Adult females, including oriental fruit fly, Bactrocera dorsalis, can sustain egg production throughout their lives provided they obtain sufficient protein. Thus, preferential attraction to food or oviposition sites (host fruit) will depend on a fly's particular physiological state. In this study, laboratory bioassays were conducted with mature, mated B. dorsalis (provisioned protein and sugar ad libitum) to evaluate attraction to traps baited with torula yeast versus six host fruit sources (guava, guava juice, mango, orange, Surinam cherry, or white sapote). Females that preferred fruit laid a significant number of eggs around the trap entrance (average 405 eggs /fly), while almost no eggs were laid by females that preferred yeast ( 0.5 and 1.3 eggs/fly on two occasions). Similar results were observed in a bioassay using headspace extracts of guava juice and torula yeast, supporting olfactory-mediated responses. When individual females were allowed to oviposit in guava juice traps 0-24 h after a choice test, $45.8 \%$ of females that chose guava juice laid eggs (average 14.7 eggs/fly), compared with $27.5 \%$ that chose yeast (average 6.5 eggs/fly). Dissections indicated that females with a preference for guava juice had an egg load 2.4 times greater than females that preferred yeast. These results suggest there is an olfactory-based behavioral switch in preference from protein to host odors when female $B$. dorsalis are oviposition-ready. We discuss the implications of our findings for practical behavioral management and detection programs for B. dorsalis.

Keywords: egg load; female attraction; food choice; host choice; invasive pest; physiological status

\section{Introduction}

Oriental fruit fly, Bactrocera dorsalis (Hendel) (Diptera: Tephritidae), is one of the most destructive invasive pests of tropical fruit and vegetable crops worldwide, with more than 430 hosts, including many important economic crops. Consequently, it poses a serious 
international trade barrier [1,2]. Although established in Hawaii since 1964 [3], B. dorsalis has not established on the U.S. mainland despite repeated incursions since its first detection in 1960 in California; however, both the frequency and size of $B$. dorsalis incursions have been accelerating. This escalates the potential for catastrophic trade disruption and reduced availability and marketability of produce, as witnessed from the 2018 B. dorsalis outbreak in Florida [4]. Current $B$. dorsalis quarantine programs focus heavily on control and surveillance of male flies using combinations of sterile insect technique, male annihilation technique, and extensive networks of male monitoring traps $[5,6]$. However, this maleoriented strategy is less effective for mitigating the impact caused by female populations, which could lead to fruit damage and ensuing trade issues.

Developing effective behavioral-based methods for the detection and control of female fruit flies has been a research priority for fruit fly management programs [7]. Protein odor and host fruit odor are two classes of volatile cues used by female fruit flies to locate protein-rich food sources and oviposition sites, respectively [8], and thus may be exploited as attractants [9-13]. It has been suggested that physiological status (e.g., mating status, age, and hunger level) has a strong influence on food and host choice decisions made by female fruit flies [14], as they may be preferentially attracted to the odor cues that are released from resources that most satisfy their needs at a given moment [15]. Thus, an unmated female fruit fly is considered more responsive to protein-based odors, while a mated, sexually mature female fly may be more interested in host fruit-based odors $[14,16]$. This is supported by electroantennography studies with the Caribbean fruit fly, Anastrepha suspensa (Loew), which demonstrated that sexually immature females have a higher olfactory response to ammonia (a protein cue), whereas mature gravid females have a higher olfactory response to $\mathrm{CO}_{2}$ (a short-range oviposition cue) $[17,18]$. In fact, extensive research has been conducted on a variety of food-based and host plant-based fruit fly attractants for the development of field lures (reviewed in $[19,20])$. In particular, for $B$. dorsalis, liquid protein-based baits, such as hydrolyzed torula yeast, have been commercially available and widely used as a female-biased attractant in management programs, although inconsistencies in trap performance have been a concern [21,22].

In terms of behavioral management, it is likely that a particular lure is attractive to only a fraction of a fruit fly population at any given time and space, as flies in an area may vary widely in age structure and physiological status [15]. Knowing what subset of females a lure can attract-i.e., understanding how physiological status influences olfactory chemoreception and female preference for food versus host fruit odors-and to what extent the preferential attraction affects fruit infestation may inform fruit fly management decisions. For example, both effective protein-based and host-based lures may be able to reduce fruit infestation, but by targeting females from different classes of physiological status. Studies have shown that a protein odor-based lure may be more effective for capture of unmated females as compared with mated ones, protein-hungry females as compared with protein-fed females, or nongravid females as compared with oviposition-ready flies; and vice versa with host fruit odor-based lures [11,16,23-25].

Although it has been suggested that female flies become more responsive to host fruit odors than to protein food odors after mating, even mated females benefit from sustained feeding on proteins, hence attraction to them, until they become ovipositionready $[26,27]$. Moreover, tephritid fruit flies can produce eggs throughout their adult period as long as they have access to protein food [28]. Therefore, females will continue to search for protein sources to supply the resources required for ovarian development and vitellogenesis [26,29]. In Bactrocera fruit flies, egg load was the most important factor that determined the behavioral switch from resource foraging to host acceptance and oviposition [30], with a significant association between continuous protein feeding and a greater degree of adult ovary development, egg load, and oviposition rate [27].

Here, we investigated the attraction of gravid $B$. dorsalis females to protein odors and host fruit odors and determined their oviposition outcome based on odor choice. All tests used mature (14-16-day-old) male and female B. dorsalis that were provided ad libitum 
access to a protein and sugar diet and mated freely after emergence from pupae. In the first set of experiments, we (i) evaluated the odor preference of mated B. dorsalis females between torula yeast and six host fruits using laboratory two-choice cage experiments, (ii) determined the most attractive host fruit source using a multiple-choice experiment, and (iii) confirmed that the $B$. dorsalis attraction was mediated by olfactory cues. In the second set of experiments, we challenged individual mated females for oviposition in response to a host fruit odor immediately after they exhibited preferential attraction to an odor source in two-choice tests, and subsequently evaluated the number of eggs laid and the internal egg load based on the odor preference of each female.

\section{Materials and Methods}

\subsection{Insects}

Bactrocera dorsalis were reared at the fruit fly rearing facility at the USDA ARS Pacific Basin Agricultural Research Center in Hilo, Hawaii. Larvae were reared on a standard wheat, sugar, and yeast diet [31]. Cohorts of flies eclosed from pupae (total 12 different generations used) were grouped over two days and held in screened cages $(30 \mathrm{~cm} \mathrm{~W} \times$ $30 \mathrm{~cm} \mathrm{~L} \times 30 \mathrm{~cm} \mathrm{H}$; shop.bugdorm.com) for two weeks at $24^{\circ} \mathrm{C}, 60-80 \% \mathrm{RH}, 12: 12 \mathrm{~L} / \mathrm{D}$ on unlimited water, sugar, and hydrolyzed yeast, and mated freely prior to testing. Three hours prior to behavioral assays, female and male flies (14-16 days old) were separated and counted in a $5{ }^{\circ} \mathrm{C}$ walk-in refrigerator [32]. These flies were considered mated as $>95 \%$ of females were mated by day 7 under similar conditions [32] and all of the 14-16-day-old females that we dissected had developed eggs.

\subsection{Host Fruits and Torula Yeast}

The test material consisted of five known host fruits of $B$. dorsalis, guava juice, and torula yeast. Locally produced mango (Mangifera indica; unknown variety) and orange (Citrus sinensis; navel) were purchased from local groceries. Common guava (Psidium guajava), Surinam cherry (Eugenia uniflora), and white sapote (Casimiroa edulis) were collected from fruit orchards in Hilo and Kona, Hawaii. All fruits were tested at ripe stage and washed in water to remove any residue. Guava juice (Meadow Gold, Hilo, HI, USA) was purchased from local groceries. Torula yeast/borax pellets were purchased from Better World Manufacturing, Inc. (Fresno, CA, USA).

\subsection{Attraction and Oviposition Response Bioassay}

Behavioral assays were conducted using a gated cup trap, an aluminum foil-covered $100 \mathrm{~mL}$ or $250 \mathrm{~mL}$ glass beaker with a cut centrifuge vial $(0.7 \mathrm{~cm}$ diameter) inserted in the center of the foil, which restricted adult flies from escaping once they enter the trap [33]. In attraction bioassays, gated cup traps were baited with one of the following: (1) a $5 \mathrm{~g}$ piece of host fruit (guava, mango, orange, Surinam cherry, or white sapote) $+30 \mathrm{~mL}$ of $0.0125 \%$ soapy water (unscented soap: Colgate-Palmolive Company, New York, NY, USA; used as drowning solution [33]), (2) $30 \mathrm{~mL}$ of guava juice, (3) $30 \mathrm{~mL}$ of torula yeast solution (5 g torula yeast $/ 30 \mathrm{~mL}$ water), (4) a rubber septum loaded with $200 \mu \mathrm{L}$ guava juice headspace extract (see below) $+30 \mathrm{~mL}$ of $0.0125 \%$ soapy water, or (5) a rubber septum loaded with $200 \mu \mathrm{L}$ torula yeast headspace extract $+30 \mathrm{~mL}$ of $0.0125 \%$ soapy water. Gated cup traps were also used to evaluate the oviposition response from female $B$. dorsalis attracted to a trap baited with different odor sources (e.g., host fruit, torula yeast). Females exhibited oviposition behavior by inserting their ovipositor into the gap between aluminum foil and cut centrifuge vial.

\subsection{Comparison of Mated B. dorsalis Attraction and Oviposition Response to Host Fruit versus} Torula Yeast

We compared the attractiveness of a host fruit source (guava, guava juice, mango, orange, Surinam cherry, or white sapote) versus torula yeast in $30 \mathrm{~cm} \times 30 \mathrm{~cm} \times 30 \mathrm{~cm}$ screened cages (shop.bugdorm.com) using a two-choice assay $(\mathrm{N}=4)$. Each cage was 
provided with two $100 \mathrm{~mL}$ gated cup traps-one baited with a host fruit source and one baited with torula yeast (see above), placed $15 \mathrm{~cm}$ apart-and a wet cotton. Mated $B$. dorsalis (50 females and 50 males) were released in each cage. After $24 \mathrm{~h}$, the number of male and female flies captured and number of eggs oviposited in gated cup traps were counted. When less than 100 eggs were oviposited, eggs were counted individually under a microscope. When more than 100 eggs were oviposited, eggs were counted volumetrically using the conversion of $1 \mathrm{~mL}$ eggs in water $=20,000$ eggs (Stephanie Gayle, personal communication).

\subsection{Selection of a Preferred Host Fruit Using Multiple-Choice Test}

The multiple-choice test $(\mathrm{N}=9)$ was conducted using $60 \mathrm{~cm} \times 60 \mathrm{~cm} \times 60 \mathrm{~cm}$ screened cages (shop.bugdorm.com) as described in [34]. Briefly, within each cage, seven $250 \mathrm{~mL}$ gated cup traps (six traps baited with one of guava, guava juice, mango, orange, Surinam cherry, and white sapote, and one trap baited with torula yeast) were randomly positioned in a circle (55 cm diameter) with equal distance $(20 \mathrm{~cm}$ apart) from each trap along the circumference. Mated B. dorsalis (100 males and 100 females) were released in each cage. The number of male and female flies captured inside each trap was counted after $24 \mathrm{~h}$.

\subsection{Headspace Volatile Collection}

To confirm whether the behavioral responses from mated $B$. dorsalis observed in the above experiments were mediated by odors of host fruit and torula yeast, headspace volatiles were collected from guava juice or torula yeast. Headspace volatiles released from the same amount of guava juice $(30 \mathrm{~mL}$ ) or torula yeast ( $5 \mathrm{~g}$ dissolved in $30 \mathrm{~mL}$ water) used in attraction and oviposition bioassays were collected using $2.4 \mathrm{~L}$ closed volatile collection chambers (ARS, Inc., Gainesville, FL, USA) with one air inlet adapter (7 mm ID) on the top and an outlet adapter ( $7 \mathrm{~mm}$ ID) on the bottom wall. Clean air was drawn into each collection chamber through an activated coconut charcoal filter, and then drawn out (0.7 L/min) through a charcoal adsorbent trap (ORBO32, Supelco Inc., Bellefonte, PA, USA) over $24 \mathrm{~h}$. Headspace volatile compounds were eluted from the adsorbent trap by rinsing with $750 \mu \mathrm{L}$ methylene chloride. The extracts were stored at $-20^{\circ} \mathrm{C}$ until use.

\subsection{Comparison of Mated B. dorsalis Attraction and Oviposition Response to Headspace Extracts of Host Fruit versus Torula Yeast}

The attraction and oviposition responses of mated $B$. dorsalis adults to headspace extracts of guava juice and torula yeast were compared using the same two-choice bioassay design described above in $30 \mathrm{~cm} \times 30 \mathrm{~cm} \times 30 \mathrm{~cm}$ screened cages $(\mathrm{N}=4)$. For treatments, $200 \mu \mathrm{L}$ of guava juice headspace extract or torula yeast headspace extract was loaded on rubber septa (Chemglass Life Science, Vineland, NJ, USA). The septum sources were prepared 60 min prior to a test. In each cage, two gated cup traps, each containing a rubber septum loaded with guava juice extract or rubber septum loaded with torula yeast extract along with $30 \mathrm{~mL}$ of $0.0125 \%$ soapy water, were provided. Mated B. dorsalis (50 males and 50 females) were released into each cage. The number of flies and number of eggs oviposited in each trap were counted after $24 \mathrm{~h}$.

\subsection{Oviposition Response of Mated B. dorsalis Attracted to Guava Juice versus Torula Yeast}

In this experiment, we compared the oviposition response and egg load from individual mated female $B$. dorsalis preferentially attracted to either host fruit odor or protein odor. To select flies with a preference for host fruit odor or protein odor, we placed two $250 \mathrm{~mL}$ gated cup traps - one baited with $30 \mathrm{~mL}$ of guava juice and one baited with $5 \mathrm{~g}$ of torula yeast $+30 \mathrm{~mL}$ water-in a $30 \mathrm{~cm} \times 30 \mathrm{~cm} \times 30 \mathrm{~cm}$ screened cage, released 30 mated $B$. dorsalis females, and live-captured individual flies as soon as they entered a trap. To facilitate the collection of live females, we inserted a mesh screen inside the trap to prevent flies from drowning inside traps.

Individual flies that chose either guava juice odor or torula yeast odor were immediately re-released into $30 \mathrm{~cm} \times 30 \mathrm{~cm} \times 30 \mathrm{~cm}$ screened cages (one fly/cage) with a $250 \mathrm{~mL}$ 
"modified" gated cup trap baited with $30 \mathrm{~mL}$ of guava juice and allowed to oviposit over $24 \mathrm{~h}(\mathrm{~N}=51)$. The modified gated traps were identical to the standard gate cup trap described above, but with the entrance to the trap (i.e., cut centrifuge vial) plugged with a piece of cotton to prevent female flies from entering the trap. The number of eggs oviposited by individual flies was monitored over three different time intervals, between 0 and $3 \mathrm{~h}, 3$ and $6 \mathrm{~h}$, and 6 and $24 \mathrm{~h}$ after fly introduction to the oviposition cage. Gated traps in each cage were replaced with a new modified gated trap at $3 \mathrm{~h}$ and $6 \mathrm{~h}$ post fly release into the cage. Th percentage of flies that oviposited was also calculated.

Egg load was also determined for individual mated B. dorsalis females that preferentially chose either guava juice odor or torula yeast odor ( $N=20$ for each). Immediately after they were captured in either guava juice or torula yeast baited traps, individual flies were released into different screened cages ( 1 fly/cage) provided with water (wet cotton) only. The abdomen of each fly was then dissected under a microscope and the number of eggs was counted (e.g., [35]).

\subsection{Statistical Analyses}

Trap capture, number of eggs oviposited, and egg load data were analyzed using a generalized linear mixed model in a randomized block design with replicate as a random factor and different bait treatments as a fixed factor using Poisson distribution with log link function and maximum likelihood estimation. The means were compared using the Tukey-Kramer test (Proc Glimmix, [36]).

\section{Results}

\subsection{Comparison of Mated B. dorsalis Attraction and Oviposition Response to Host Fruit versus Torula Yeast}

Significantly more mated females were captured in traps baited with any of the six host fruit sources than in traps baited with torula yeast (mango: $\mathrm{F}_{1,3}=58.15, p=0.0047$; orange: $\mathrm{F}_{1,3}=64.18, p=0.0041$; guava juice: $\mathrm{F}_{1,3}=72.35, p=0.0034$; guava: $\mathrm{F}_{1,3}=82.08$, $p=0.0028$; white sapote: $\mathrm{F}_{1,3}=74.29, p=0.0033$; Surinam cherry, $\mathrm{F}_{1,3}=75.06, p=0.0032$; Figure 1).

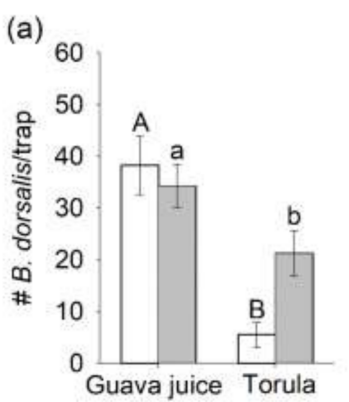

(d)

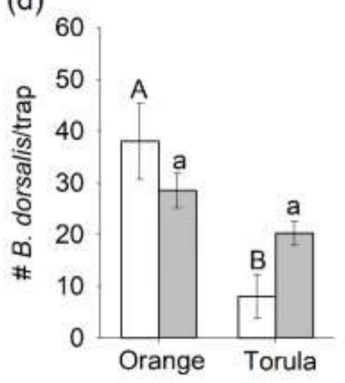

(b)

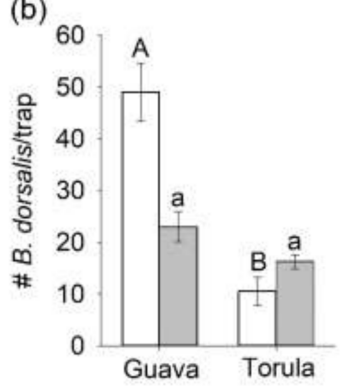

(e)

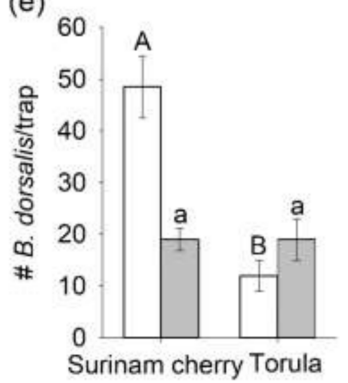

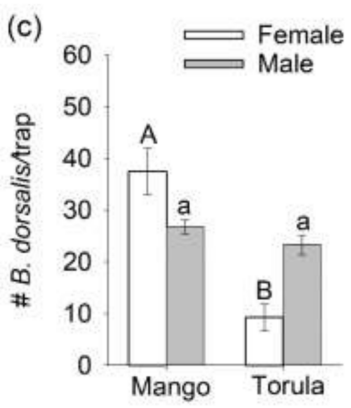

(f)

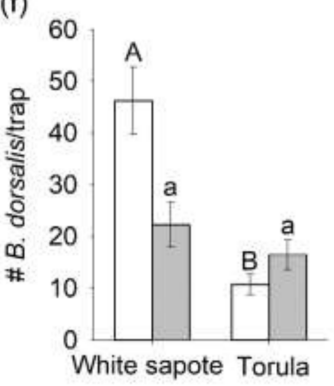

Figure 1. Mean $( \pm \mathrm{SEM})$ numbers of mated male and female Bactrocera dorsalis flies captured in traps baited with torula yeast and one of the six host fruit sources ((a) guava juice, (b) guava, (c) mango, (d) orange, (e) Surinam cherry, and (f) white sapote) in two-choice laboratory assays. For a given sex, different letters on bars indicate significant differences by Tukey-Kramer tests at $p<0.05$. 
In contrast, there were no significant differences in the number of male flies captured in traps baited with a host fruit source or torula yeast (all $p$-values $>0.1000$ ), except for guava juice baited traps, which captured significantly more males than torula yeast baited traps $\left(\mathrm{F}_{1,3}=11.95, p=0.0407\right)$. Female flies attracted to a host fruit source oviposited a significantly greater number of eggs ( $>200$ eggs / trap) than females attracted to torula yeast (mango: $\mathrm{F}_{1,3}=61.64, p=0.0043$; orange: $\mathrm{F}_{1,3}=57.18, p=0.0048$; guava juice: $\mathrm{F}_{1,3}=51.16$, $p=0.0056$; guava: $\mathrm{F}_{1,3}=47.66, p=0.0062$; white sapote: $\mathrm{F}_{1,3}=168.13, p=0.0001$; Surinam cherry, $F_{1,3}=83.31, p=0.0028$; Figure 2). A total of only seven eggs were oviposited in traps baited with torula yeast (two eggs in one torula yeast trap in the Surinam cherry bioassay and five eggs in a torula yeast trap in the white sapote assay), even though $41 \%$ of females chose torula yeast baited traps in two-choice assays.
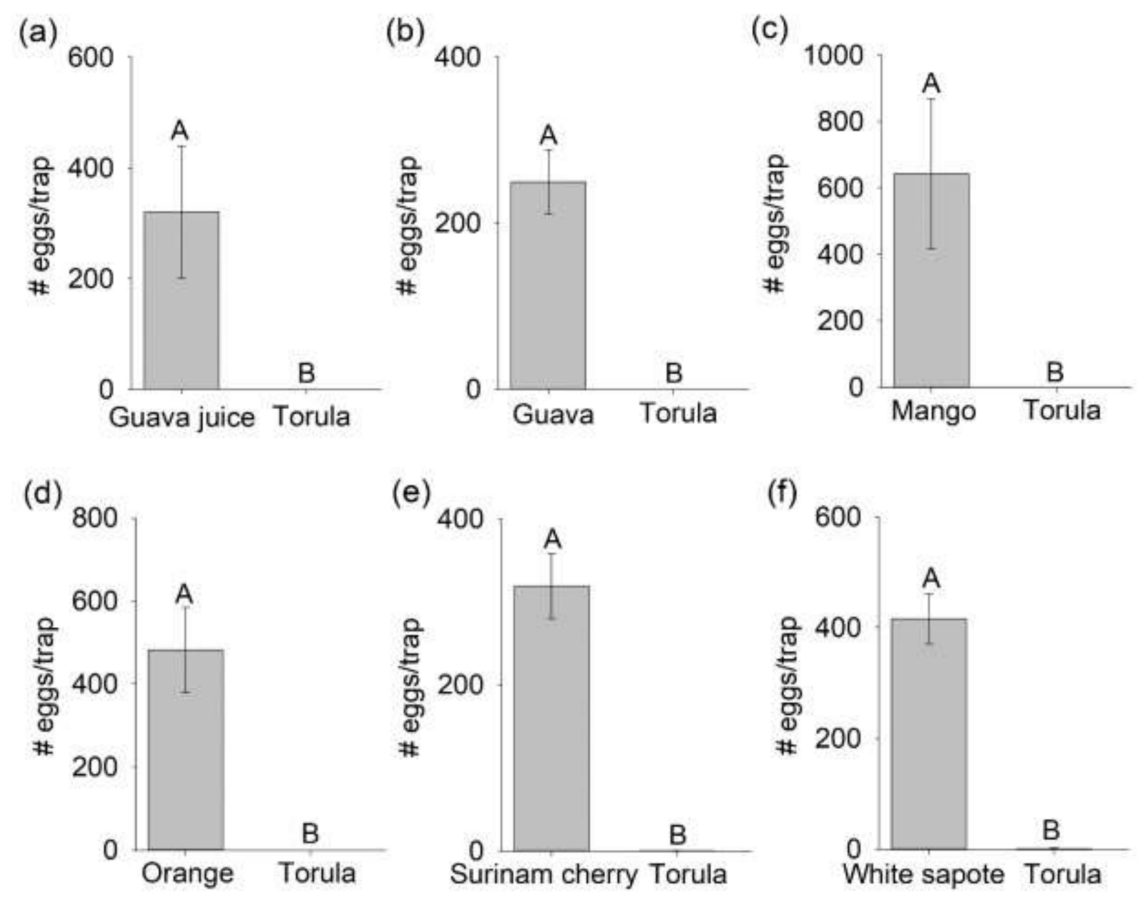

Figure 2. Number of Bactrocera dorsalis eggs (mean \pm SEM) oviposited in gated cup traps baited with either torula yeast and one of the six host fruit sources ((a) guava juice, (b) guava, (c) mango, (d) orange, (e) Surinam cherry, and (f) white sapote) in two-choice laboratory assays. Different letters on bars indicate significant differences by Tukey-Kramer tests at $p<0.05$.

\subsection{Selection of a Preferred Host Using Multiple-Choice Test}

When traps baited with guava, guava juice, mango, orange, Surinam cherry, and white sapote were compared simultaneously, traps baited with either guava juice or mango captured significantly greater numbers of female flies than traps baited with torula yeast; however, the greatest number of females was captured in traps baited with guava juice $\left(\mathrm{F}_{6,48}=25.73, p<0.0001\right.$, Figure 3$)$. For male flies, traps baited with torula yeast captured the greatest number of flies and there were no significant differences among numbers captured in traps baited with torula yeast, guava juice, or Surinam cherry $\left(\mathrm{F}_{6,48}=12.59\right.$, $p<0.0001$, Figure 3). 


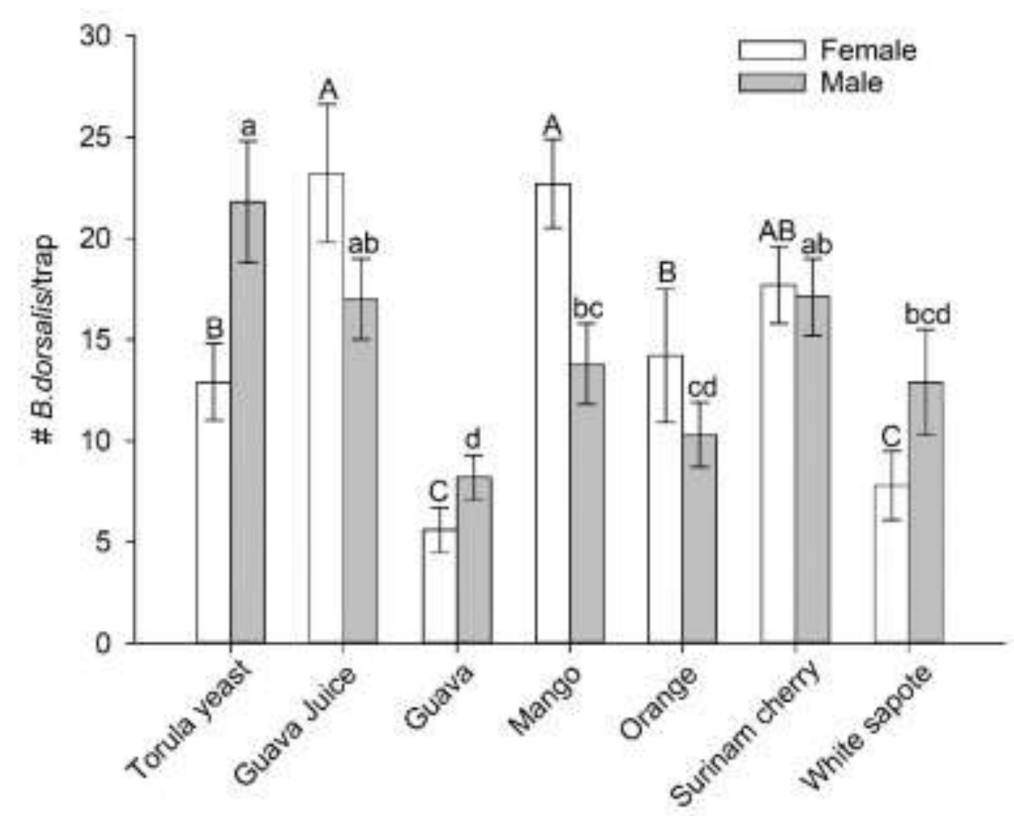

Figure 3. Mean $( \pm \mathrm{SEM})$ numbers of mated male and female Bactrocera dorsalis flies captured in traps baited with torula yeast and six different host fruit sources in multiple-choice laboratory assays. For a given sex, different letters on bars indicate significant differences by Tukey-Kramer tests at $p<0.05$.

3.3. Comparison of Mated B. dorsalis Attraction and Oviposition Response to Headspace Extracts of Host Fruit versus Torula Yeast

Attraction and oviposition response of mated $B$. dorsalis to guava juice and torula yeast odors released from rubber septa (Figure 4) were similar to that observed with the actual guava juice and torula yeast in the previous experiment (Figures 1 and 2). Traps baited with guava juice headspace extract captured significantly greater numbers of male and female flies than traps baited with torula yeast headspace extract (female, $\mathrm{F}_{1,3}=22.97$, $p=0.0173$, male, $\mathrm{F}_{1,3}=11.71, p=0.0418$, Figure $4 \mathrm{a}$ ). In addition, mated females oviposited a significantly greater number of eggs in traps baited with guava juice headspace extract than in traps baited with torula yeast headspace extract (zero eggs in torula yeast baited traps: $F_{1,3}=18.97, p=0.0224$; Figure $4 b$ ).
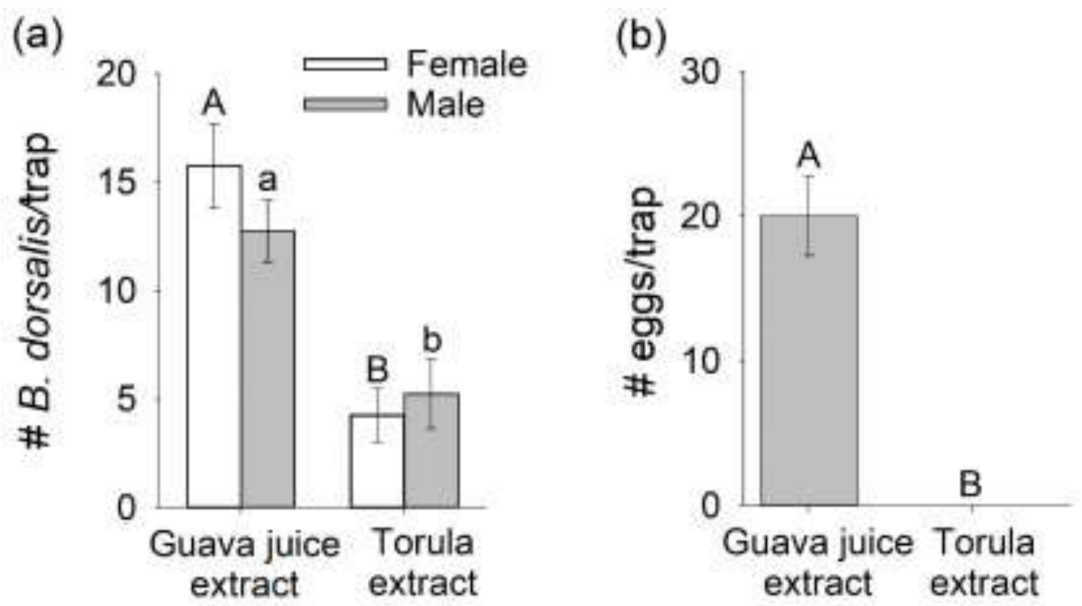

Figure 4. Mean ( \pm SEM) numbers of (a) mated male and female Bactrocera dorsalis flies captured and (b) eggs oviposited in traps baited with headspace extracts of guava juice and torula yeast in two-choice laboratory assays. For a given sex, different letters on bars indicate significant differences by Tukey-Kramer tests at $p<0.05$. 


\subsection{Oviposition Response from Mated B. dorsalis Preferentially Attracted to Guava Juice versus Torula Yeast}

When individual mated B. dorsalis females that chose guava juice or torula yeast were challenged to oviposit in response to guava juice odor over $24 \mathrm{~h}$, the oviposition rates (\%) from flies that preferred guava juice were 85,69 , and $50 \%$ greater than oviposition rates from females that chose torula yeast during the $0-3,3-6$, and $6-24 \mathrm{~h}$ post-choice period, respectively (Figure 5a). Comparing females that chose guava juice or torula yeast odor and successfully oviposited, the average number of eggs laid by females that chose guava juice was 2.2, 3.1, and 2.1 times greater than that laid by females that chose torula yeast during the $0-3,3-6$, and $6-24 \mathrm{~h}$ post-choice time intervals, respectively $\left(0-3 \mathrm{~h}: \mathrm{F}_{1,98}=240.8\right.$, $p<0.0001 ; 3-6$ h: $\mathrm{F}_{1,98}=129.16, p<0.0001 ; 6-24$ h: $\mathrm{F}_{1,98}=98.77, p<0.0001$; Figure 5b). The response of mated $B$. dorsalis females to host fruit odor and torula yeast odor appeared to be related to egg load. The average egg load of females that preferred guava juice odor was 2.1 times greater than the egg load of flies that preferred torula yeast odor $\left(\mathrm{F}_{1,19}=467.97\right.$, $p<0.0001$; Figure 5c).

(a)

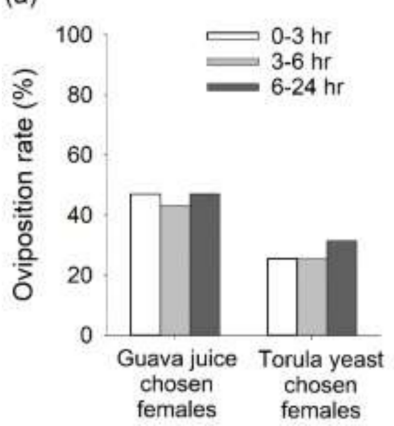

(b)

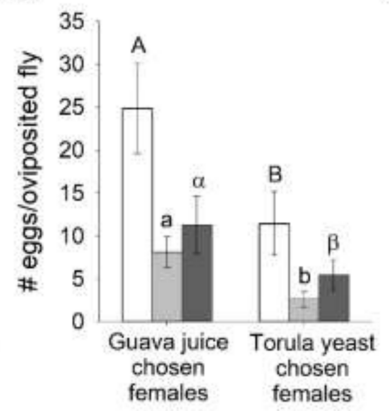

(c)

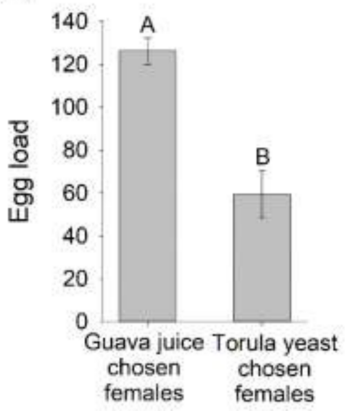

Figure 5. Oviposition responses (a,b) and egg load (c) from mated female Bactrocera dorsalis immediately after individual female flies made a choice between guava juice or torula yeast. Oviposition responses were evaluated at $0-3,3-6$, and 6-24 h post-choice period. Different letters indicate significant difference between guava juice and torula yeast by Tukey-Kramer tests at $p<0.05$.

\section{Discussion}

Our results show that considerable variation exists for olfactory preference and oviposition outcome among the cohorts of 14-16-day-old mated B. dorsalis females fed an unlimited diet of sugar, hydrolyzed protein, and water. Although a significantly greater number of mated females preferred the odors emitted from host fruit over the odor from torula yeast, about $41 \%$ of the females were still preferentially attracted to the odor from torula yeast. Mated females that differed in odor preference also exhibited significant differences in egg load and oviposition outcome. Females that preferred host fruit odor had an egg load 405 times greater than females that preferred torula yeast odor. When these flies were challenged to oviposit immediately after they made a choice between host fruit and protein odors, $45.8 \%$ of the female B. dorsalis that chose host fruit odor laid eggs during the $24 \mathrm{~h}$ post-choice period, while only $27.5 \%$ of females that chose torula yeast laid eggs. Moreover, among those flies that did oviposit, females attracted to host fruit odor laid 2.4 times more eggs than females attracted to torula yeast. Together, these results suggest that mated female $B$. dorsalis with a preference for host fruit odor are likely to be in an imminent oviposition-ready physiological status, while mated females that prefer torula yeast odor are likely more protein-hungry and need to ingest more protein to build up a critical egg load necessary for oviposition [23,27,28,37-39].

The findings on differential oviposition outcomes from gravid B. dorsalis with differential olfactory preferences are in agreement with previous studies. These studies suggest that (1) tephritid fruit flies show compensatory feeding patterns on limited resources at a given moment (e.g., protein deprived flies are more interested in ingesting protein than other resources such as sugar; [40]); (2) younger flies are more attracted to a protein source than host 
fruit as protein ingestion is necessary to become reproductively active $[17,24,26,27,29,41,42]$; (3) mated and older females become more attracted to host fruit than protein food, which is related to host acceptance and oviposition $[11,16,17,24,25,30,43,44] ;$ (4) fruit flies with a greater egg load have a greater oviposition outcome [27]; and (5) fruit flies with a greater amount of protein ingestion have a greater egg load [45]. Our results add to these studies and provide data that even similarly aged mated cohorts of female $B$. dorsalis, with the same diet history, can exhibit differential olfactory preferences for protein food and host fruit odors, preferences that are dependent on female physiological status and have a direct impact on their oviposition outcome. We recognize that our findings are based on 14-16day-old females. In the field, the temporal distribution of females ready for oviposition is often unknown. Thus, future studies will evaluate whether similar outcomes are observed from females with a wider age distribution.

From a management perspective, although it has been generally suggested that a protein-based attractant is more effective for the capture of young unmated female $B$. dorsalis, while a host fruit-based attractant is more effective for mated females $[11,13,25,43,46]$, our results strongly suggest that a protein-based attractant should still be effective for the capture of mated, but less oviposition-ready female B. dorsalis. Moreover, the proportion of these protein-hungry females is likely even greater under field conditions, considering that protein is a limited resource in habitats of tropical fruit flies [47] and that B. dorsalis tested in our study had unlimited access to protein and sugar as adults and larvae. This suggests that an effective protein-based attractant may be attractive to a larger proportion of fruit flies in the field than previously predicted [48].

Our results also support the potential usefulness of a host-based attractant in female $B$. dorsalis management programs. The current study documented a clear preference for host fruit odors by oviposition-ready $B$. dorsalis females, the proportion of the pest population that poses a direct threat to fruit production. In tandem with an effective repellent applied to fruit trees, a perimeter of traps baited with a host-based lure can be deployed using a 'push-pull' strategy to reduce the number of oviposition-ready females [49]. Alternatively, an array of traps combining host-based and protein-based lures may improve detection and suppression efforts by targeting females of different physiological status. With A. suspensa, there is synchronous maturation of eggs within ovarioles, resulting in cyclical increases in the egg load and oviposition of 'batches' of eggs [26]. Therefore, when a female has a mature batch of eggs to lay, she will be more attracted to host odors; however, once the batch is laid, she will switch preference to protein odors to complete maturation of the next batch of eggs. Together, these results suggest that both protein-based and host fruit-based attractants may play valuable roles in reducing fruit infestation by targeting $B$. dorsalis females with differential physiological needs.

Protein baits such as torula yeast solutions have been used as an attractant for female B. dorsalis $[4,21]$. The bait is effective for both male and female flies, but is considered to be a weak attractant, especially compared with strong male lures such as methyl eugenol [50]. Liquid protein baits are also difficult to maintain and service, not user friendly, not specific, and known for inconsistencies in effectiveness [51-54]. The inconsistencies in trap attractiveness may be related to fluctuations in protein bait odor profiles, which are affected by biotic (e.g., microbial growth) and abiotic conditions surrounding the trap [19]. Understanding the key essential protein bait odor compounds that are directly responsible for fruit fly attraction may help overcome the inconsistency. Work is currently in progress to identify the key attractant compounds released from the headspace of protein baits preferred by female $B$. dorsalis to develop more consistent and user-friendly female lures that can replace protein baits. Practical application of host fruit odor-based attractants in the field is still limited for B. dorsalis [55], although there have been studies to identify host-based attractants $[13,43,46]$. The results from the multiple-choice assay suggest that guava juice and other fruit volatiles could be a good source for the development of a synthetic attractant for $B$. dorsalis females, especially close to oviposition. Work is under way to develop an attractive female lure particularly effective for oviposition-ready $B$. dorsalis 
in the field and to test whether capturing oviposition-ready B. dorsalis actually results in a reduction in fruit infestation.

Author Contributions: Conceptualization, G.-H.R., P.E.K. and D.H.C.; Formal analysis, G.-H.R.; Funding acquisition, P.E.K. and D.H.C.; Investigation, G.-H.R.; Methodology, G.-H.R. and D.H.C.; Writing-original draft, G.-H.R., P.E.K. and D.H.C.; Writing-review and editing, G.-H.R., P.E.K. and D.H.C. All authors read and approved the final version of the manuscript.

Funding: Animal and Plant Health Inspection Service: IA60-6038-9-001.

Institutional Review Board Statement: Not applicable.

Informed Consent Statement: Not applicable.

Acknowledgments: We thank Ken Love for providing various species of host fruits and Stephanie Gayle for providing $B$. dorsalis pupae. This research was supported in part by an Interagency Agreement between USDA-APHIS and USDA-ARS (\# IA60-6038-9-001) to P.E.K. and D.H.C. and an appointment to the ARS Research Participation Program, an agreement between the U.S. Department of Energy (DOE) and the USDA, managed under DOE contract number DE-SC0014664. The opinions, findings, conclusions, or recommendations expressed in this publication are those of the authors and do not necessarily reflect the views of the USDA. USDA is an equal opportunity provider and employer.

Conflicts of Interest: The authors declare no conflict of interest.

\section{References}

1. Weems, H.V.; Heppner, J.B.; Nation, J.L.; Steck, G.J. Oriental Fruit Fly, Bactrocera dorsalis (Hedndel) (Insecta: Diptera: Tephritidae); EENY-083, IFAS Extension; University of Florida: Gainesville, FL, USA, 2016; Available online: https://edis.ifas.ufl.edu/ publication/IN240 (accessed on 7 June 2021).

2. Dohino, T.; Hallman, G.J.; Grout, T.G.; Clarke, A.R.; Follett, P.A.; Cugala, D.R.; Tu, D.M.; Murdita, W.; Hernandez, E.; Pereira, R.; et al. Phytosanitary treatments against Bactorocera dorsalis (Diptera: Tephritidae): Current situation and future prospects. J. Econ. Entol. 2017, 110, 67-79.

3. Steiner, L.F.; Mitchell, W.C.; Harris, E.J.; Kozuma, T.T.; Fujimoto, M.S. Oriental fruit fly eradication by male annihilation. J. Econ. Entomol. 1965, 58, 961-964. [CrossRef]

4. Steck, G.J.; Fox, A.J.; Carrillo, D.; Dean, D.; Roda, A.; Epsky, N.D.; Smith, T.R. Oriental fruit fly eradication in Florida 2015-2016: Program implementation, unique aspects, and lessons learned. Am. Entomol. 2019, 65, 108-121. [CrossRef]

5. Cunningham, R.T.; Suda, D.Y. Male annihilation through mass-trapping of male flies with methyl eugenol to reduce infestation of oriental fruit fly (Diptera: Tephritidae) larvae in papaya. J. Econ. Entomol. 1986, 79, 1580-1582. [CrossRef]

6. Vargas, R.I.; Mau, R.F.L.; Jang, E.B.; Faust, R.M.; Wong, L. The Hawaii fruit fly area-wide pest management program. In Areawide Pest Management: Theory and Implementation; Koul, O., Cuperus, G.W., Elliott, N.C., Eds.; CABI Publishing: Wallingford, UK, 2008; pp. 300-325.

7. Shelly, T.; Epsky, N.D.; Jang, E.; Reyes-Flores, J.; Vargas, R. Trapping and the Detection, Control, and Regulation of Tephritid Fruit Flies; Springer: Dordrecht, The Netherlands, 2014.

8. Fletcher, B.; Prokopy, R.J. Host location and oviposition in tephritid fruit flies. In Reproductive Behavior of Insects; Bailey, W.J., Ridsdill-Smith, J., Eds.; Chapman and Hall: New York, NY, USA, 1991; pp. 139-171.

9. Robacker, D.C.; Heath, R.R. Attraction of Mexican fruit flies (Diptera: Tephritidae) to lures emitting host-fruit volatiles in a citrus orchard. Fla. Entomol. 1996, 79, 600-602. [CrossRef]

10. Prokopy, R.J.; Hu, X.P.; Jand, E.B.; Vargas, R.I.; Warthen, J.D. Attraction of mature Ceratitis capitate females to 2-heptanone a component of coffee fruit odour. J. Chem. Ecol. 1998, 24, 1293-1304. [CrossRef]

11. Cornelius, M.L.; Nergel, L.; Duan, J.J.; Messing, R.H. Responses of female oriental fruit flies (Diptera: Tephritidae) to protein and host fruit odours in field cage and open field tests. Environ. Entomol. 2000, 29, 14-19. [CrossRef]

12. Barry, J.D.; Miller, N.W.; Pinero, J.C.; Tuttle, A.; Mau, R.F.L.; Vargas, R.I. Effectiveness of protein baits on melon fly and oriental fruit fly (Diptera: Tephritidae): Attraction and feeding. J. Econ. Entomol. 2006, 99, 1161-1167. [CrossRef] [PubMed]

13. Siderhurst, M.; Jang, E. Female-biased attraction of oriental fruit fly, Bactrocera dorsalis (Hendel), to a blend of host fruit volatiles from Terminalia catappa L. J. Chem. Ecol. 2006, 32, 2513-2524. [CrossRef]

14. Prokopy, R.J.; Drew, R.A.; Sabine, B.N.; Lloyd, A.C.; Hamacek, E. Effect of physiological and experiential state of Bactrocera tryoni flies on intra-tree foraging behavior for food (bacteria) and host fruit. Oecologia 1991, 87, 394-400. [CrossRef]

15. Díaz-Fleischer, F.; Piñero, J.C.; Shelly, T.E. Interactions between tephritid fruit fly physiological state and stimuli from baits and traps: Looking for the Pied Piper of Hamelin to lure pestiferous fruit flies. In Trapping and the Detection, Control, and Regulation of Tephritid Fruit Flies; Shelly, T., Epsky, N., Jang, E.B., Reyes-Flores, J., Vargas, R., Eds.; Springer: Dordrecht, The Netherlands, 2014; pp. 145-172. 
16. Miller, N.W.; Vargas, R.I.; Prokopy, R.J.; Mackey, B.E. State dependent attractiveness of protein bait and host fruit odor to Bactrocera cucurbitae (Diptera: Tephritidae) females. Ann. Entomol. Soc. Am. 2004, 97, 1063-1068. [CrossRef]

17. Kendra, P.E.; Montgomery, W.S.; Mateo, D.M.; Puche, H.; Epsky, N.D.; Heath, R.R. Effect of age on EAG response and attraction of female Anastrepha suspensa (Diptera: Tephritidae) to ammonia and carbon dioxide. Environ. Entomol. 2005, 34, 584-590. [CrossRef]

18. Kendra, P.E.; Montgomery, W.S.; Epsky, N.D.; Heath, R.R. Electroantennogram and behavioral responses of Anastrepha suspensa (Diptera: Tephritidae) to putrescine and ammonium bicarbonate lures. Environ. Entomol. 2009, 38, 1259-1266. [CrossRef]

19. Epsky, N.D.; Kendra, P.E.; Schnell, E.Q. History and development of food-based attractants. In Trapping and the Detection, Control, and Regulation of Tephritid Fruit Flies; Shelly, T., Epsky, N., Jang, E.B., Reyes-Flores, J., Vargas, R., Eds.; Springer: Dordrecht, The Netherlands, 2014; pp. 75-118.

20. Tan, K.H.; Nishida, R.; Jang, E.B.; Shelly, T.E. Pheromones, male lures, and trapping of tephritid fruit flies. In Trapping and the Detection, Control, and Regulation of Tephritid Fruit Flies; Shelly, T.E., Epsky, N., Jang, E.B., Reyes-Flores, J., Vargas, R.I., Eds.; Springer: Dordrecht, The Netherlands, 2014; pp. 15-74.

21. Piñero, J.C.; Mau, R.F.L.; Vargas, R.I. Managing oriental fruit fly, Bactrocera dorsalis (Diptera: Tephritidae), through spinosad-based protein bait sprays and sanitation in papaya orchards in Hawaii. J. Econ. Entomol. 2009, 102, 1123-1132. [CrossRef]

22. Shelly, T.; Kurashima, R.; Fezza, T. Field evaluation of three-component solid food-based dispenser versus torula yeast for capturing Mediterranean and oriental fruit flies (Diptera: Tephritidae). J. Asia Pac. Entomol. 2020, 23, 825-831. [CrossRef]

23. Robacker, D.C. Specific hunger in Anastrepha ludens (Diptera: Tephritidae): Effects on attractiveness of proteinaceous and fruit-derived lures. Environ. Entomol. 1991, 20, 1680-1686. [CrossRef]

24. Prokopy, R.J.; Vargas, R.I. Attraction of Ceratitis capitata (Diptera: Tephritidae) flies to odor of coffee fruit. J. Chem. Ecol. 1996, 22, 807-820. [CrossRef] [PubMed]

25. Cornelius, M.L.; Duan, J.J.; Messing, R.H. Volatile fruit odours as attractants for the oriental fruit fly (Diptera: Tephritidae). J. Econ. Entomol. 2000, 93, 93-100. [CrossRef]

26. Kendra, P.E.; Montgomery, W.S.; Epsky, N.D.; Heath, R.R. Assessment of female reproductive status in Anastrepha suspensa (Diptera: Tephritidae). Fla. Entomol. 2006, 89, 144-151. [CrossRef]

27. Wang, F.; Chambi, C.; Li, Z.; Huang, C.; Ma, Y.; Li, C.; Tian, X.; Sangija, F.; Ntambo, M.S.; Kankonda, O.M.; et al. Influence of supplemental protein on the life expectancy and reproduction of the Chinese citrus fruit fly, Bactrocera minax (Enderlein) (Tetradacus minax) (Diptera: Tephritidae). J. Insect Sci. 2018, 18, 25. [CrossRef]

28. Papaj, D.R. Ovarian dynamics and host use. Annu. Rev. Entomol. 2000, 45, 423-448. [CrossRef]

29. Aluja, M.; Birke, A.; Guillen, L.; Díaz-Fleischer, F.; Nestel, D. Coping with an unpredictable and stressful environment: The life history and metabolic response to variable food and host availability in a polyphagous tephritid fly. J. Insect Physiol. 2011, 57, 1592-1601. [CrossRef] [PubMed]

30. Migani, V.; Ekesi, S.; Hoffmeister, T.S. Physiology vs. Environment: What drives oviposition decisions in mango fruit flies (Bactrocera invadens and Ceratitis cosyra)? J. Appl. Entomol. 2014, 138, 395-402. [CrossRef]

31. Tanaka, N.; Steiner, L.F.; Ohinata, K.; Okamoto, R. Low-cost larval rearing medium for mass production of oriental and Mediterranean fruit flies. J. Econ. Entomol. 1969, 62, 967-968. [CrossRef]

32. Jang, E.B.; Carvalho, L.A.; Stark, J.D. Attraction of female oriental fruit fly, Bactrocera dorsalis, to volatile semiochemicals from leaves and extracts of a non host plant, Panax (Polyscias guilfoylei) in laboratory and olfactometer assays. J. Chem. Ecol. 1997, 23, 1389-1401. [CrossRef]

33. Cha, D.H.; Adams, T.; Rogg, H.; Landolt, P.J. Identification and field evaluation of fermentation volatiles from wine and vinegar that mediate attraction of spotted wing drosophila. Drosophila Suzukii. J. Chem. Ecol. 2012, 38, 1419-1431. [CrossRef]

34. Cha, D.H.; Roh, G.H.; Hesler, S.P.; Wallingford, A.; Stockton, D.G.; Park, S.K.; Loeb, G.M. 2-Pentylfuran: A Novel Repellent of Drosophila Suzukii. Pest Manag. Sci. 2021, 77, 1757-1764. [CrossRef]

35. Chou, M.Y.; Mau, R.F.L.; Jang, E.B.; Vargas, R.I.; Pinero, J.C. Morphological features of the ovaries during oogenesis of the oriental fruit fly, Bactrocera dorsalis, in relation to the physiological state. J. Insect Sci. 2012, 12, 144. [CrossRef] [PubMed]

36. SAS Institute. SAS/STAT 9.2 User's Guide, 2nd ed.; SAS Institute Inc.: Cary, NC, USA, 2009.

37. Robacker, D.C.; Moreno, D.S.; Demilo, A.B. Attractiveness to Mexican fruit flies of combinations of acetic acid with ammonium/amino attractants with emphasis on effects of hunger. J. Chem. Ecol. 1996, 22, 499-511. [CrossRef]

38. Prokopy, R.J.; Resilva, S.S.; Vargas, R.I. Post-alighting behavior of Ceratitis capitata flies on odor baited traps. Fla. Entomol. 1996, 79, 422-428. [CrossRef]

39. Manrakhan, A.; Lux, S.A. Effect of food deprivation on attractiveness of food sources, containing natural and artificial sugar and protein, to three African fruit flies: Ceratitis cosyra, Ceratitis fasciventris, and Ceratitis capitata. Ent. Exp. Appl. 2008, 127, 133-143. [CrossRef]

40. Cohen, H.; Voet, H. Effect of physiological state of young Ceratitis capitata females, on resource foraging behaviour. Entomol. Exp. Appl. 2002, 104, 345-351. [CrossRef]

41. Tsitsipis, J.A. Nutrition: Requirements. In World Crop Pests, Fruit Flies: Their Biology, Natural Enemies and Control; Robinson, A.S., Hooper, G., Eds.; Elsevier: Amsterdam, The Netherlands, 1989; Volume 3, pp. 103-119.

42. Aluja, M.; Díaz-Fleischer, F.; Papaj, D.R.; Lagunes, G.; Sivinski, J. Effects of age, diet, female density, and the host resource on egg load in Anastrepha ludens and Anastrepha obliqua (Diptera: Tephritidae). J. Insect Physiol. 2001, 47, 975-988. [CrossRef] 
43. Jayanthi, K.P.D.; Woodcock, C.M.; Caulfield, J.; Birkett, M.A.; Bruce, T.J.A. Isolation and identification of host cues from mango, Mangifera indica, that attract gravid female oriental fruit fly, Bactrocera dorsalis. J. Chem. Ecol. 2012, 38, 361-369. [CrossRef] [PubMed]

44. Jayanthi, K.P.D.; Kempraj, V.; Aurade, R.M.; Venkataramanappa, R.K.; Namdagopal, B.; Verghese, A.; Bruce, T.J.A. Specific volatile compounds from mango elicit oviposition in gravid Bactrocera dorsalis females. J. Chem. Ecol. 2014, 40, 259-266. [CrossRef] [PubMed]

45. Meats, A.; Leighton, S.M. Protein consumption by mated, unmated, sterile and fertile adults of the Queensland fruit fly, Bactrocera tryoni and its relation to egg production. Physiol. Entomol. 2004, 29, 176-182. [CrossRef]

46. Jayanthi, P.D.K.; Kumar, P.S.; Vyas, M. Odour cue from fruit arils of Artocarpus heterophyllus attract both sexes of oriental fruit flies. J. Chem. Ecol. 2021, 47, 552-563. [CrossRef]

47. Drew, R.A.I.; Yuval, B. The evolution of fruit fly feeding behavior. In Fruit Flies (Tephritidae): Phylogeny and Evolution of Behavior; Aluja, M., Norrbom, A.L., Eds.; CRC Press: Boca Raton, FL, USA, 2000; pp. 731-749.

48. Zhou, X.W.; Niu, C.Y.; Han, P.; Desneux, N. Field evaluation of attractive lures for the fruit fly Bactrocera minax (Diptera: Tephritidae) and their potential use in spot sprays in Hubei Province (China). J. Econ. Entomol. 2012, 105, 1277-1284. [CrossRef] [PubMed]

49. Byers, J.A.; Maoz, Y.; Cohen, B.; Golani, M.; Fefer, D.; Levi-Zada, A. Protecting avocado trees from ambrosia beetles by repellents and mass trapping (push-pull): Experiments and simulations. J. Pest Sci. 2021, 94, 991-1002. [CrossRef]

50. Omoy, T.R.; Sudarwohadi, S.; Soelakson, S. The attractive ability of methyl eugenol and protein hydrolisate against fruit fly on hot pepper. J. Hort. 1999, 6, 469-476.

51. Revis, H.C.; Miller, N.W.; Vargas, R.I. Effects of aging and dilution and toxicity of GF120 fruit fly bait spray for melon fly control in Hawaii. J. Econ. Entomol. 2004, 97, 1659-1665. [CrossRef] [PubMed]

52. Leblanc, L.; Vargas, R.I.; Rubinoff, D. Captures of pest fruit flies (Diptera: Tephritidae) and nontarget insects in BioLure and torula yeast traps in Hawaii. Environ. Entomol. 2010, 39, 1626-1630. [CrossRef]

53. Leblanc, L.; Vargas, R.I.; Rubinoff, D. Attraction of Ceratitis capitata (Diptera: Tephritidae) and endemic and introduced nontarget insects to BioLure bait and its individual components in Hawaii. Environ. Entomol. 2010, 39, 989-998. [CrossRef] [PubMed]

54. Navarro-Llopis, V.; Vacas, S. Mass trapping for fruit fly control. In Trapping and the Detection, Control, and Regulation of Tephritid Fruit Flies; Shelly, T., Epsky, N., Jang, E.B., Reyes-Flores, J., Vargas, R., Eds.; Springer: Dordrecht, The Netherlands, 2014; pp. 513-555.

55. Alyokhin, A.V.; Messing, R.H.; Duan, J.J. Visual and olfactory stimuli and fruit maturity affect trap captures of oriental fruit flies (Diptera: Tephritidae). J. Econ. Entomol. 2000, 93, 644-649. [CrossRef] [PubMed] 